\title{
Teorias curriculares, perspectivas teóricas em Educação Física Escolar e implicações para a formação docente
}

CDD. 20.ed. 371.12

796.017

\author{
Osvaldo Luiz FERRAZ* \\ Walter Roberto CORREIA* \\ *Escola de Educa- \\ ção Física e Esporte, \\ Universidade de São \\ Paulo.
}

\section{Resumo}

A função do professor de educação física escolar pode ser definida pela elaboração, implantação e avaliação de programas que tematizam, do ponto de vista didático-pedagógico, jogos, esportes, lutas, ginásticas, danças, exercícios físicos, entre outros; com a intenção de influenciar a formação dos alunos para a participação democrática na vida em sociedade. Todavia, este consenso se dilui quando aplicado ao campo do currículo e da formação docente. No campo do currículo, apesar do reconhecimento de que a tematização didático-pedagógica se faz a partir de sentidos culturais e das potencialidades de estimulação do organismo humano que se apresentam nas manifestações da cultura de movimento; a intencionalidade, a organização curricular e a sistematização do conhecimento podem divergir consideravelmente modificando o papel do componente curricular na educação básica. Sendo assim, este texto analisa aspectos do desenvolvimento das teorias curriculares, relacionando-as às perspectivas teóricas em Educação Física. Em seguida, implicações deste debate são relacionadas à formação docente.

UnITERMOS: Educação física escolar; Currículo; Formação docente.

\section{Introdução}

Atualmente, pode-se afirmar que há um consenso na área profissional e acadêmica em Educação Física Escolar de que a função precípua do professor de educação física na escola é a de elaborar, implementar e avaliar programas de ensino que tematizam, do ponto de vista didático-pedagógico, os jogos, os esportes, as lutas, as ginásticas, as danças, os exercícios físicos, as atividades rítmicas e etc., com propósitos educacionais explícitos e implícitos, ou seja, com a intenção de influenciar a formação dos sujeitos para a participação democrática na vida em sociedade. Todavia, este consenso se dilui quando aplicado ao campo do currículo e da formação de professores(as).

No campo do currículo escolar, apesar do reconhecimento de que a tematização didáticopedagógica se faz a partir de sentidos culturais e das potencialidades de estimulação do organismo humano que se apresentam nas manifestações da cultura de movimento ligadas à tradição da Educação Física (Betti, Ferraz \& Dantas, 2011), a intencionalidade, a organização curricular e a sistematização do conhecimento pode divergir consideravelmente modificando o papel do componente curricular na escolarização básica.

No que diz respeito a formação docente AzANHA (2000) e Carvalho (1997) defendem que a instituição escolar, concomitantemente às características específicas das práticas das disciplinas curriculares, devem ser objeto fundamental de estudo e reflexão dos cursos de licenciatura. Segundo os autores, a formação do professor não pode ser imaginada como a simples e direta aplicação à situação de ensino de um saber teórico. Diferentemente de outras profissões, o exercício da formação docente só é possível a partir do quadro institucional da escola. Nesse sentido, o ponto de vista pedagógico não é uma soma de parcelas de saberes teóricos que, embora necessários, não são suficientes para a compreensão da vida escolar.

Ainda, segundo os autores, a principal crítica é o de que as disciplinas que compõem as Licenciaturas em geral estão distantes de uma adequada visão das tarefas, objetivos e problemas concretos do cotidiano de uma instituição escolar. Sendo assim, os cursos de 
licenciatura precisam fugir do modelo de formação calcado na caracterização de uma figura abstrata de um profissional dotado de determinadas qualidades, como sendo um ideal de formação.

Portanto, para abordar esse tema "Teorias curriculares, perspectivas teóricas em educação física escolar e implicações para a formação docente" optamos, neste artigo, por analisar aspectos do desenvolvimento das teorias curriculares para a educação escolar, relacionando-as às perspectivas teóricas em Educação Física Escolar. Em seguida, discutimos algumas das implicações deste debate para a formação docente.

\section{Teorias curriculares e perspectivas teóricas em Educação Física Escolar}

Ao longo da história da pedagogia a noção de currículo ganhou muitos significados e essas definiçôes ainda influenciam as concepções e práticas pedagógicas dos professores(as) nas escolas.

O sentido etimológico da palavra currículo (termo latino "curriculum") expressa movimento progressivo, pista de corrida, caminho a ser percorrido. No contexto educacional, a noção de currículo tem abarcado proposições diversas englobando referenciais curriculares propostos pelas redes de ensino, grade curricular com disciplinas e atividades, conjunto de planos de ensino dos professores(as), aquilo que acontece na sala de aula e experiências vividas pelos alunos na escola, entre outros.

O conceito de currículo inicialmente utilizado na Europa e nas Colônias Americanas tinha o sentido estrito de matéria, até o final do século XIX. Em 1902, com a publicação do livro "The child and the curriculum" de John Dewey, a definição vai se enriquecendo, pois a partir da crítica aos currículos utilizados nas escolas daquela época apontava-se para a construção de um currículo que valorizava os interesses do aluno e o papel importante atribuído à experiência para a aprendizagem escolar. Percebe-se assim a ampliação do sentido dado a noção de currículo para além da matéria, incorporando a dimensão do ensino e da aprendizagem (LOPES \& MACEDO, 2011).

A noção de currículo como um objeto de estudo e pesquisa aparece pela primeira vez nos Estados Unidos no início do século XX, na década de 20. Em conexão com o processo de industrialização e movimentos migratórios vigente na época, intensificou-se a necessidade de escolarização da população. Sistemas administrativos educacionais mobilizaram-se para racionalizar o processo de construção, desenvolvimento e avaliação de currículos (SIIVA, 2009).

Ainda, segundo o autor, um marco importante desse movimento pode ser expresso pela publicação do livro de John Franklin Bobbitt - The Curriculum (1918)- cuja definição de currículo está relacionada à especificação precisa de objetivos, procedimentos e métodos para a obtenção de resultados que possam ser mensurados. De tal modo, nota-se a aproximação com o processo de industrialização e da administração científica de Taylor.

Outra obra fundamental para a constituição do currículo como campo de estudo foi o livro "Princípios básicos de currículo e ensino", publicado por Ralph Tyler em 1949, que respondia a quatro questôes básicas: como selecionar objetivos, como selecionar experiências de aprendizagem, como organizar essas experiências e como avaliar sua eficácia. Essa perspectiva incorpora, nos processos de seleção e organização do conteúdo e das atividades de aprendizagem, elementos como a eficiência e racionalidade técnica que vão dominar o campo de estudos curriculares até os anos de 1960 aproximadamente. Além disso, a partir da denominada "guerra fria" entre soviéticos e americanos surge também a preocupação com o sentido do conteúdo nos currículos das escolas americanas, pois estes deveriam formar os cientistas e líderes daquela nação para fazer frente ao avanço científico e tecnológico do bloco comunista (LOPES \& MACEDO, 2011).

$\mathrm{Na}$ década de 70 aparece o movimento denominado reconceptualista que se expande nas décadas seguintes. Willian F. Pinar em seu livro denominado "Curriculum theorizing: the reconceptualists (1975)" propõe as bases que se contrapõem às características da racionalidade burocrática e tecnológica presentes nos modelos de Bobbitt de 1918 e de Tyler de 1949. O pressuposto é o de que toda a atividade intelectual educacional implica em uma dimensão política, uma vez que o currículo está imbricado em um processo social mais amplo e, por isso, deve se libertar das influências hegemônicas da tradição técnica (LOPES \& MACEDO, 2011; Silva, 2009).

A crítica às abordagens de currículo vigentes mais contundentes surge com uma tendência denominada Nova Sociologia da Educação que se desenvolve 
na Inglaterra, na década de 70, tendo como marco o livro editado por Michael Young "Knowledge and Control: new direction for the Sociology of Education". Nos Estados Unidos estudiosos como Henry Giroux e Michael Apple também se contrapõem à abordagem técnica e corroboram a tendência de enfatizar o caráter político dos estudos de currículo.

Segundo PaCheco (2005) a diferença básica é a de que na tradição técnica o currículo significa "o conjunto de todas as experiências planificadas no âmbito da escolarização dos alunos, vinculando-se a aprendizagem aos planos de instrução que determinam os resultados e valorizam os fundamentos de uma psicologia de natureza comportamentalista" (p.33) e, na tradição filiada a uma perspectiva prática e emancipatória o fundamento básico está na interrelação dos diversos níveis de decisão, definindo currículo como "um projeto que resulta não só no plano das intenções, bem como do plano de sua realização no seio de uma estrutura organizacional" (p.33). Ou seja, o currículo articula as intenções prévias e as experiências vividas pelos alunos dentro do contexto escolar, mas com um propósito bastante flexível e aberto, pois depende das condições de sua aplicação que engloba as decisões oriundas das estruturas políticas e das estruturas escolares.

Em que pese à noção de currículo ter abarcado proposições diversas ao longo da história, há um aspecto comum entre essas perspectivas, ou seja, a ideia de organização de experiências de aprendizagem realizadas por docentes a fim de desenvolver um processo educativo. Sendo assim, a organização da experiência escolar dos alunos mediante princípios de globalidade estrutural e de sequenciação da experiência educacional está presente nas atuais e consolidadas noções de currículo.

Uma questão central a qualquer dessas perspectivas de currículo é a definição de qual conhecimento deve ser ensinado. As teorias curriculares recorrem a discussões sobre a natureza humana, sobre a natureza do conhecimento, da cultura e da sociedade para definir qual conhecimento e saberes são considerados essenciais para fazer parte do currículo. Desenvolvese, portanto, critérios de seleção para se definir em um universo amplo de conhecimentos e saberes aqueles que são importantes para formar a pessoa que se deseja educar. Tomáz Tadeu da SILVA (2009) indaga:

Qual o tipo de ser humano desejável para um tipo de sociedade? Será a pessoa racional e ilustrada do ideal humanista de educação? Será a pessoa otimizadora e competitiva dos modelos neoliberais de educação? Será a pessoa ajustada aos ideais de cidadania do moderno estado nação? Será a pessoa desconfiada e crítica dos arranjos sociais existentes preconizada nas teorias educacionais críticas? (p.15).

Nesse sentido, para o autor, a cada modelo de ser humano corresponderá um tipo de conhecimento e de currículo adequado. Portanto, currículo é muito mais do que um programa escolar e um rol de disciplinas. Ele é uma ação pedagógica coletiva que se fundamenta numa concepção de homem e de sociedade, implicando em atitudes frente às relações sociais e políticas. Percebe-se que, para além das questôes do conhecimento, o currículo se relaciona com a noção de identidade, ou seja, naquilo que somos e naquilo que nos tornamos e, portanto, com as noções de identidade e subjetividade (SILVA, 2009).

No cenário educacional brasileiro, o Ministério de Educação e Cultura/Conselho Nacional de Educação elaborou Diretrizes Curriculares Nacionais - DCNs, para todas as etapas da Educação Básica (BRASIL, 2010). As DCNs consideram a autonomia das escolas para a elaboração das suas propostas pedagógicas e, incentivam essas instituições a organizar seu currículo selecionando, dentro das áreas de conhecimento, os conteúdos que consideram fundamentais para a formação das competências explicitadas nos documentos (DCNs). Dessa forma é possível adaptar o conteúdo às demandas regionais, aos aspectos locais relevantes e à população que a escola atende.

As DCNs são leis que especificam metas e objetivos que se caracterizam em orientaçóes gerais para as escolas, redes e sistemas de ensino. As Diretrizes Curriculares Nacionais para a Educação Básica foram publicadas em 2010. Todavia, as diretrizes específicas para cada ciclo foram fixadas, a saber: Educação Infantil em 2009, Ensino Fundamental em 2010 e, Ensino Médio em 2011. Sua construção foi legitimada pela participação de diferentes entidades da sociedade brasileira, tais como: Associação Nacional de Pós-Graduação e Pesquisa em Educação (ANPED), Conselho Nacional de Secretários de Educação (CONSED), União Nacional dos Dirigentes Municipais de Educação (UNDIME), docentes, pesquisadores, dirigentes municipais e estaduais de ensino, representantes da rede privada, entre outros.

As novas Diretrizes Curriculares procuram atender a atual realidade econômica, cultural e social. Entretanto, elas serão complementadas com outro documento denominado "Expectativas de Aprendizagem" que identifica os conhecimentos que os alunos deverão saber ao final de cada ciclo ou série de escolarização. Ao contrário dos Parâmetros 
Curriculares Nacionais (BRASIL, 1997, 1998a, 1998b) este documento terá um caráter normativo que deverá ser observado pelas escolas, redes e sistemas de ensino na elaboração dos currículos e projetos pedagógicos. Sua publicação está prevista para o final de 2012.

O pressuposto é o de que a obrigatoriedade deverá garantir conhecimentos básicos e comuns a todos os alunos do país, independentemente da região. Por isso o desafio é determinar qual é esse conhecimento, levando-se em conta uma diversidade de contextos regionais.

Um problema sério nesse campo de debate é a imprecisão conceitual. Sabe-se que diretrizes curriculares são amplas e genéricas e que apontam direções e princípios a seguir, enquanto que as expectativas de aprendizagem explicitam o que se espera que todos os alunos aprendam, ao concluírem uma série ou nível de ensino. Defensores do documento junto ao poder público argumentam que as tais "expectativas de aprendizagem" dizem respeito a orientaçōes para auxiliar o professor no planejamento curricular e que incluem informações sobre materiais e tempo de trabalho necessário à sua prática pedagógica. $\mathrm{O}$ problema é que não se sabe qual é o nível de especificidade dessas expectativas de aprendizagem em relação aos conteúdos que o documento irá explicitar.

Se por um lado, a definição específica dos conteúdos - prescrição - diminui a autonomia dos professores(as) e não considera a diversidade de condiçôes das escolas; por outro, documentos muito genéricos, como foi o caso dos Parâmetros Curriculares Nacionais, trouxeram dificuldades para os professores(as) na organização do ensino de determinados temas.

Ainda, nesse debate da "prescrição versus autonomia" das proposiçóes curriculares, um aspecto importante é a escolha dos conteúdos em um currículo prescritivo. Quais critérios devem nortear a seleção de alguns conteúdos em detrimento de outros? Como combater a excessiva influência das avaliações nacionais como, por exemplo, o ENEM e a Prova Brasil na determinação do que deve ser ensinado? Sabe-se que esses exames acabam delimitando demasiadamente os conteúdos a ser ensinado nas escolas, o que caracteriza uma distorção inaceitável.

Outra consequência importante decorrente do debate das teorias curriculares é o impacto nos cursos de formação de professores(as) que discutiremos a seguir.

A principal crítica ao desdobramento da racionalidade de Tyler na construção curricular alega que os objetivos curriculares devem surgir da negociação em sala de aula, entre alunos e professores(as), e que estes últimos são os legítimos organizadores do currículo. Os professores(as) são os que podem, mais adequadamente, apreciar, criticar e eleger o que é mais relevante para compor o currículo em seus contextos singulares. Essa seria a melhor maneira de contrapor a fragilidade das abordagens técnicas que mantém um hiato entre os planos curriculares pré-determinados ou oficiais e a sua aplicação (EINSNER, 1967).

Esta constatação influencia diretamente o paradigma dos cursos de formação de docente, pois os professores(as) apresentam uma maneira particular de aproveitamento e utilização de informaçôes teóricas e de organizações curriculares em sua prática (CARDOSO, 1997). Além disso, vários estudiosos, nesse campo, tem reconhecido que a formação e o desenvolvimento profissional é um processo permanente e é influenciado pelo modo como o professor pensa e age nas diferentes situações da vida, ou seja, englobando a vida pessoal e profissional (BRASIL, 2002; SACRISTÁN \& Pérez Gómez, 2000; TARdif, 2000).

Em suma, a questão do currículo implica uma demanda premente para formação dos professores(as) na perspectiva dos saberes docentes, uma vez que a configuração curricular nos remete para um campo de contestação simbólica, marcada por conflitos e tensões a partir de embates de classes, gêneros, etnias, culturas e lógicas formais e informais pelos mais diversos interlocutores socioculturais. Dito de outra forma, as proposiçôes de currículo, que perpassam a autonomia relativa de professores(as) estarão invariavelmente atreladas às estruturas de poder.

Segundo Canen e Moreira (2001), o currículo como cultura e projeto é derivado de um conjunto de ênfases e omissões, cujas escolhas se dão a partir do universo amplo da cultura, o quê, por sua vez, implicará em ressonâncias desiguais em relação aos diversos grupos que compóe uma determinada realidade social e educativa. A seleção dos saberes escolares expressa inequivocamente uma posição política e pedagógica produzindo uma assimetria na relação entre os saberes e poderes na educação e, sobretudo, na constituição identitária dos sujeitos e protagonistas envolvidos na cena educativa.

O currículo é um campo de contestação e, sobretudo, não consensual. Segundo sua perspectiva, muitas "vozes" poderiam ser autorizadas para proferir uma concepção legitimadora e de autoridade para validação de certas formas de configurações curriculares. O currículo como consubstancialização das intenções educativas, tanto explícitas como ocultas, são perpassadas dinamicamente pelos eventos das esferas macro e micro do sistema educacional. 
Entretanto, a prática social do currículo escolar esta ancorada no espectro e dinamismo da cultura e, assim sendo, questões fundamentais que expressam sua complexidade precisam ser objeto de reflexão e de análise, tais como: A quem se destina determinada proposição curricular?; O currículo expressa o que a escola realiza ou deixa de realizar?; Se a tematização didático-pedagógica se faz a partir de sentidos culturais ligados a uma tradição que pode ou deve renovar-se, como se modificar para não se desatualizar?

Ainda nessa perspectiva, SACRISTÁN (2000) alerta para a dificuldade em se ordenar em um único discurso ou paradigma de currículo, todas as funçôes e potencialidades educativas do currículo escolar, tendo em vista o entrecruzamento dinâmico e dialético das mais diferentes matrizes epistemológicas e políticas sobre cada sistema ou realidade educativa. Sob essa perspectiva, ainda sinaliza para o fato de que as intençôes educativas orientadas e formatadas curricularmente, não se constituem em realidades abstratas, tampouco em objetos ou práticas à margem do sistema educacional. Sob a ótica do referido estudioso em currículos, as práticas e proposições curriculares apresentadas aos professores(as) e aos alunos são constructos históricos investidos e subsidiados por uma trama política e cultural que demandam por uma problematização que traga à tona os seus sentidos, significados e desdobramentos sociais.

Nessa perspectiva, LoRo (1999) interroga os aspectos relativos aos processos de legitimação e validação dos propósitos e conteúdos escolares, bem como as condições de sua produção e viabilização:

O currículo "fala" de alguns sujeitos e ignora outros; conta histórias e saberes que, embora parciais, se pretendem universais, as ciências, as artes e as teorias trazem a voz daqueles que se auto-atribuíram a capacidade de eleger as perguntas e construir as respostas que supostamente, são de interesse de toda sociedade. Qual é, no entanto, a história da produção dessa ciência, que é escrita em letras maiúsculas? Por que alguns saberes não podem integrar o currículo? Em que condiçôes foram produzidas as teorias que sustentam o pensamento pedagógico? Que sujeito universal é esse de que falam as teorias psicológicas e de aprendizagem? Que condições provocam transformaçôes na linguagem e nas suas regras? Quem tem legitimidade para conhecer? Quem pode afirmar que algo se constitui em problema a ser estudado? São inúmeros os processos implicados na constituição diferenciada dos sujeitos (p.88).
Assim sendo, podemos reeditar certas questões recorrentes, que balizam todo e qualquer debate curricular em que se pretenda fazer emergir seus componentes essenciais, como por exemplo: Quem faz a seleção dos conteúdos da escola? A quem servem os conteúdos a serem ensinados na escola? O que pode ser considerado de valor educativo no processo de socialização dos conhecimentos escolares? De onde são provenientes os saberes curriculares? $\mathrm{O}$ que justifica e caracteriza o saber da escola? Como o saber docente determina o potencial educativo de uma proposição curricular? Como o não saber docente se constitui como limite ou possibilidade ao projeto político e pedagógico da escola?

A explicitação das questões acima mencionadas são evidências das "dobraduras" da complexidade curricular. Esses questionamentos são expressões de uma pequena parte das "faces" da multidimensionalidade constitutiva do currículo. Seu dinamismo está constituído de uma inerente polissemia atribuída pelos principais atores sociais das práticas escolares, ou seja, professores(as), alunos, pais e comunidade. Nessa trama, a "polifonia" da diversidade humana constitutiva do "palco escolar" impõe o desafio de uma integração da desigualdade de saberes e poderes no processo de elaboração e validação das experiências escolares. Dessa forma, se faz pertinente o destaque de Sacristán e Pérez Gomes (2000) a respeito dos processos de negociação curricular entre os protagonistas da escola, como forma de superação das contradições, ambivalências, paradoxos e conflitos que se manifestam tacitamente no cotidiano escolar:

De qualquer forma, na aula sempre acontece um processo explícito ou disfarçado de negociação, relaxada ou tensa, abertamente desenvolvida ou provocada por meio de resistências não confessadas. (...) Assim, o processo de socialização acontece sempre através de um complicado e ativo movimento de negociação em que as reações e resistências de professores/as e alunos/as como indivíduos ou como grupos podem chegar a recusa e ineficiência das tendências reprodutoras da instituição escolar (p.19).

A Educação Física como componente curricular na educação brasileira tem sua presença sustentada desde o século XIX. Sua permanência pode indicar que o conhecimento que está contido na ideia de componente, tem alguma eficácia social nas mais diferentes conjunturas sociais pelas quais podemos inserir a dialética "escola e sociedade".

Ao longo do seu processo evolutivo, as práticas sustentadas pelos professores(as) de Educação 
Física foram alicerçadas por diferentes matrizes conceituais e práticas sociais que, de alguma forma, produziram uma relativa e controversa eficácia aos propósitos educacionais. Nessa historicidade, concepções como "modelos ginásticos europeus", "métodos desportivos generalizados", "tecnicismo esportivizante", "movimento do corpo humano", "educação motora", "corporeidade", "cultura corporal" e o "se-movimentar", são expressões ou, até mesmo, resultantes dos embates sociais internos e externos da Educação Física, sobretudo, dos interesses corporativos da esfera profissional (médicos, militares, esportistas, professores(as) de educação física e pedagogos) e das redes epistemológicas (pesquisadores, acadêmicos e universidades). $\mathrm{Na}$ educação em geral, podemos identificar também o fenômeno de interesses corporativos e/ou políticos ideológicos gravitando perenemente em relação ao currículo das escolas e das políticas educacionais.

Provavelmente, talvez esse aspecto seja uma das múltiplas variáveis ou condicionantes que impedem a constância e o investimento responsável no desenvolvimento de políticas públicas de educação. A "volatilidade" ou "liquidez" dos processos de construção e amadurecimento de propostas curriculares produzem ressonâncias nefastas às instâncias de formação docente. Por que ensinar, o quê ensinar, como ensinar, para quem ensinar, ou seja, questóes cruciais de viabilização do currículo são significantes produzidos em esferas alheias aos domínios das instituiçôes escolares e de seus atores concretos. As instâncias técnicas de planejamentos dos departamentos públicos de educação e as universidades são concebidas e investidas de um "pressuposto saber" que, nem sempre reconhecem o saberes produzidos pelos protagonistas diretos do cotidiano escolar. Entendemos aqui como saberes a ensinar e para ensinar, tanto as práticas e soluções da ação tácita pedagógica de professores(as), alunos e alunas e a comunidade, como os dilemas e as incertezas que perpassam as realizações escolares.

A Educação Física Escolar contemporânea dispõe de um arcabouço histórico conceitual formulado por diferentes matrizes teóricas produzidos no âmbito acadêmico dos últimos 30 anos. A partir do movimento de cientificização da área impulsionado pelo sistema de pós-graduação, diferentes perspectivas teóricas foram produzidas, cujos constructos e proposições subsidiaram os processos de formação docente e ensaios curriculares. A partir de leituras subsidiadas por campos como da Filosofia, Psicologia, Antropologia, Biologia, Semiótica, Política e outros, foi possível resignificar os propósitos e a especificidade do componente e produzir, dessa maneira, um conjunto de inferências pedagógicas para sua inserção curricular.

Nessa conjuntura foram produzidas concepções de análise pedagógica de natureza psicomotricista, desenvolvimentista, construtivista, crítico-superadora, crítico-emancipatória, progressista, sistêmica, antropológica, saúde/renovada, fenomenológica, e pós-crítica, entre outras. Essa produção foi incorporada nas mais diversas esferas, das universidades às reformas curriculares nos níveis federal, estadual e municipal. Podemos considerar que esse patrimônio teórico conceitual/propositivo, serviu de inspiração para muitos interlocutores da Educação Física no contexto escolar. Todavia, é preciso relembrar que essas leituras e interpretações do sentido e significado do componente curricular Educação Física no contexto da escolarização, emergiram de investimentos acadêmicos "ancorados" nos domínios da própria Educação Física e, não necessariamente, mediados com as outras lógicas/concepções do pensamento curricular brasileiro. Dito de outra maneira, vislumbramos a dificuldade de transposição dessas perspectivas teóricas para a sua profícua efetivação nas práticas educacionais concretas. Cabe aqui destacar que parte do discurso pedagógico da Educação Física produzido nas últimas décadas, não se configuraram como práticas sistematizadas no rigor que esse termo exige. Entretanto, por mais que dispuséssemos de uma multiplicidade de "leituras" e "ensaios propositivos" para o fomento de iniciativas curriculares, esses instrumentais de "pretensão" ou "tipificação metodológica", se configuraram em perspectivas de análise e não propriamente em abordagens de currículo.

Todavia, atualmente encontramos proposições para a Educação Física Escolar oriundas, sobretudo, de Secretarias Municipais e Estaduais de ensino público que se constituem em propostas curriculares efetivas. Esta parece ser uma tendência positiva no campo das teorizaçooes curriculares em educação física, mas que ainda carecem de um programa de formação de professores(as) adequado às demandas do sistema educacional. 


\section{Implicações para a formação docente}

As questôes acima mencionadas produzem demandas impactantes aos domínios dos saberes docentes e, especialmente, para seus processos de formação inicial e continuada. Mesmo considerando a importância da perspectiva da construção coletiva do projeto político e pedagógico pela comunidade escolar, o papel dos docentes na elaboração curricular é nuclear. Segundo a Lei de Diretrizes e Bases da Educação Nacional - art.13 - (BRASIL, 1996) os docentes incumbir-se-ão de:

I) Participar da elaboração da proposta pedagógica do estabelecimento do ensino;

II) Elaborar e cumprir plano de trabalho, segundo a proposta pedagógica do estabelecimento do ensino;

III) Zelar pela aprendizagem dos alunos;

IV) Estabelecer estratégias de recuperação para os alunos de menor rendimento;

V) Ministrar os dias letivos e horas estabelecidos, além de participar integralmente dos períodos dedicados ao planejamento, à avaliação e ao desenvolvimento profissional;

VI) Colaborar com as atividades de articulação da escola com as famílias e a comunidade.

Além disso, os Referenciais para Formação de Professores (BRAsIL, 2002) propóe que o desenvolvimento profissional dos professores(as) seja contínuo devido a, pelo menos, quatro exigências:

a) Incremento acelerado e as mudanças rápidas no conhecimento científico, na cultura, nas artes, nas tecnologias da comunicação; elementos básicos do currículo escolar;

b) A inevitável transformação das formas de pensar, sentir e atuar das novas gerações de alunos em função da evolução acelerada da sociedade em suas estruturas materiais, institucionais e nas formas de organização da convivência, dos modelos de produção e de distribuição de renda; c) Avanço das investigaçóes no campo do conhecimento profissional do professor que o capacita para intervir, experimentar e refletir sobre sua própria prática e sobre o valor e pertinência dos projetos pedagógicos que desenvolve;

d) Próprio processo de desenvolvimento pessoal do professor que o leva a transformar suas crenças, valores, hábitos, atitudes e formas de se relacionar com a vida e consequentemente com a sua profissão (p.6).

Essas atribuições de caráter genérico estabelecidas pelos instrumentos legais e normativos contém em si, uma complexidade premente no que tange às competências e habilidades docentes. Essas mesmas são remetidas para todos os componentes curriculares e seus respectivos protagonistas. Dessa forma, podemos questionar que conhecimentos são necessários para dar suporte aos docentes para viabilizarem os mais distintos projetos curriculares?

Corroborando com o posicionamento de SACRISTÁN (2000) de que a complexidade do currículo não admite simplificaçôes ou reduçōes e, tampouco, possa ser subsidiado por um único referencial teórico, entendemos que a produção de conhecimento curricular e docente devam demandar outras lógicas de produção e legitimação. Temos aqui, a percepção de que a produção de conhecimento sobre currículo deverá invariavelmente estar articulada com a dimensão dos saberes docentes, dada a relevância dessa dialética inerente a qualquer pretensão de eficácia educacional.

Nesse sentido, TARDIFF (2000) reivindica como uma demanda premente na produção de práticas escolares e saberes docentes, a noção de uma epistemologia da prática. Os conhecimentos necessários para composição dos projetos pedagógicos não podem dispensar os saberes e as lógicas acumuladas pela historicidade das práticas docentes. A tarefa docente contém em si um dinamismo peculiar entre reflexão e ação que se situa no primado da ação. Os saberes docentes e curriculares são produzidos sob contextos e circunstâncias muito diferenciadas entre professores(as) e acadêmicos. As condições de trabalho, os significados e os símbolos de suporte ao trabalho, os dilemas e as soluçōes, o "status" e a valorização social desses grupos estão imersos em contingências muito diferenciadas. Essa premissa impacta de forma patente as condições de construção curricular e dos saberes docentes necessários à prática educativa. A busca dos educadores é pela eficácia, é uma lógica de síntese e de tendência eclética, imposta pela complexidade do ambiente e pela natureza da tarefa docente. $\mathrm{O}$ trabalho em aula para os docentes é expressão de algo mais profundo do que a execução de uma tarefa a ser avaliada.

O currículo compreendido como algo para além de programas ou a justaposição linear de disciplinas escolares, exige o reconhecimento do que se produz e do que se produziu no seio da escola e nos sistemas educativos. Os modismos pedagógicos como o "didatismo", "marxismo" e o "cognitivismo" (TARDIFF, 2000), como formas de sobreposição dos saberes eruditos de natureza acadêmica aos saberes práticos e tácitos dos educadores foram ineficazes. Não é mais 
admissível apagar o patrimônio cultural desenvolvido pela memória pedagógica das escolas, que na sua realização cotidiana, está encarnada nos corpos docentes e discentes. Essa memória, mesmo sendo imprecisa, paradoxal ou, até mesmo, contraditória é, ainda assim, imprescindível como ponto de partida e de ligação para a viabilização da experiência cultural denominada currículo.

Atualmente, persiste em muitos sistemas de educação a formação docente e o fomento de programas curriculares com a lógica da racionalidade instrumental e técnica, formalista e instrutiva. Essas são insistentemente gestadas no devaneio elitista e conservador das comunidades departamentais e técnicas da educação, presumindo que os docentes necessitam serem ilustrados na sua "desinformação" sendo esses passíveis de "redenção pedagógica" a partir de cursos de atualização acadêmica.

No tocante a essa questão, IMBERNÓn (2010) nos alerta para a importância de conhecermos de onde viemos para aonde vamos do ponto de vista da formação de professores(as). A compreensão do processo evolutivo das experiências em formação docente é indispensável para uma melhor prospecção de objetivos e recursos mais apropriados às novas e mutantes demandas educacionais:

É necessário conhecer os elementos da herança formadora que nos permitam continuar construindo e oferecer alternativas de inovação e mudança às políticas e práticas de formação. Ninguém pode negar que a realidade social, o ensino, a instituição educacional e suas finalidades do sistema educacional evoluíram e que, como consequência, os professores devem sofrer uma mudança radical em sua forma de exercer a profissão e em seu processo de incorporação e formação (p.13).

Ainda sob essa ótica, é fundamental buscar novas alternativas na formação docente, fortalecendo e valorizando aspectos como o respeito e o resgate da identidade e do protagonismo do professorado. Para tanto, é preciso considerar os educadores como sujeitos reflexivos, no reconhecimento e legitimação de seus dilemas e soluçōes. Esse processo não pode prescindir da luta pelas condiçōes efetivas de melhoria e dignificação de suporte e viabilização do magistério. Segundo esse mesmo estudioso, é necessário efetuar uma adequação das ideias pedagógicas às políticas e às práticas educativas em ação para compor e ampliar o processo de formação dos professores(as). A formação docente com vistas a produzir um impacto sobre a produção da cultura curricular, demanda a superação do individualismo nas relaçôes entre os docentes, procurando insistentemente alcançar a dimensão colaborativa. Esforços nessa direção são necessários para superar a condição da falsa colegialidade que contribui para a fragmentação das intenções e realizações curriculares.

Uma formação docente de vanguarda nos impele na direção da criaçãao de espaços de formação, com especial destaque, para a otimização dos espaços e tempos da própria escola. A escola é um ateliê para os atores da composição pedagógica. Nesse cenário a formação deve privilegiar as situaçōes problemáticas dos professores(as), assumindo que a complexidade deve ser desafiada com a coragem docente. Aqui se torna imprescindível a consideração das atitudes e emoçōes docentes como demanda fundamental no desenvolvimento desses recursos humanos para educação.

Sendo assim, a Educação Física Escolar, deve estabelecer um reposicionamento na produção dos conhecimentos curriculares de forma articulada com a produção dos saberes docentes, a partir do lado de dentro dos muros da escola. Portanto, conceber a escola como "lócus" de experiência e produção de saberes, se torna indispensável para própria sustentabilidade do sistema educativo.

A volatilidade das conveniências políticas a cada mudança de governo e entidade político-partidária tem usurpado recursos públicos do sistema educativo. Isso implica convocar os interlocutores da academia a assumirem uma posição ética junto a historicidade da escolarização. Aqui propomos o abandono do personagem ilustrador para o colaborador solidário na composição de soluções aos professores(as) que honram corajosamente uma imagem ancestral de inspiração civilizatória, ou seja, o mito do mestreaprendiz. É possível e desejável uma produção de conhecimento para sustentação de uma Educação Física pertinente aos tempos atuais que ainda não foi nomeada. Que seja fruto da tecitura prática e reflexiva de autores e autoras docentes incógnitos ou anônimos que estão localizados nesse extenso território que é o sistema educativo brasileiro.

Sabemos que existem muitas formas de sentir, pensar e fazer a Educação Física nas escolas que não foram descritas e "dissecadas" pelas teorias pedagógicas, mas que certamente, produzem múltiplas culturas corporais de movimento. É imperativa uma aproximação acadêmica e profissional para subsidiar um projeto curricular crítico e inovador que honre as demandas de uma Educação Física Escolar compatível com as demandas do contemporâneo. Esse saber pode estar disposto no próprio "corpo" escolar. 


\begin{abstract}
Curriculum theories, theoretical perspectives in physical education and implications for school teacher training

The function of the teacher of physical education can be defined by the development, implementation and evaluation of programs that analyze, from the point of view didactic-pedagogic, games, sports, wrestling, gymnastics, dance, exercise, among others, with the intention of influence the student's formation for democratic participation in society. However, this consensus dissolves when applied to the field of curriculum and teacher training. In the field of curriculum, despite the recognition that the schematization didactic-pedagogic makes up from cultural meanings and potential stimulation of the human organism that is present in the manifestations of the culture of movement; intentionality, curriculum organization and systematization of knowledge may differ considerably modifying the role of curricular component. Therefore, this paper analyzes aspects of the development of curriculum theories and relate them to theoretical perspectives in Physical Education. Then implications of this debate are related to teacher training.
\end{abstract}

UnITERMS: Physical education; Curriculum; Teacher training.

\title{
Resumen
}

Teorias curriculares, perspectivas teóricas en educación física y las implicaciones con la formación docente

La función del profesor de educación física escolar puede ser definida por la elaboración, implantación y evaluación de programas que tematizan, desde el punto de vista didáctico-pedagógico, juegos, deportes, luchas, gimnasia, danzas, ejercicios físicos, entre otros; con la intención de influenciar la formación de los alumnos para la participación democrática de la vida en sociedad. Todavía, este consenso se diluye cuando es aplicado al campo del currículo y de la formación docente. En el campo del currículo, a pesar del reconocimiento de que la tematización didáctico-pedagógica se hace a partir de los sentidos culturales y de las potencialidades de estimulación del organismo humano que se presentan en las manifestaciones de la cultura del movimiento; la intencionalidad, la organización curricular y la sistematización del conocimiento pueden divergir considerablemente modificando el papel del componente curricular en la educación básica. Siendo así, este texto analiza aspectos del desarrollo de las teorías curriculares, relacionándolas a las perspectivas teóricas en Educación Física. En seguida, las implicaciones de este debate son relacionadas a la formación docente.

PalABRAS Clave: Educación física escolar; Teorias curriculares; Formación docente.

\section{Referências}

AZANHA, J.M.P. Uma reflexão sobre a formação do professor da escola básica. São Paulo: Conselho Estadual de Educação de São Paulo, 2000. [Processo 64/69, 28-06-2000].

BETTI, M.; FERRAZ, O.L.; DANTAS, L.E.P.B.T. Educação física escolar: estado da arte e direções futuras. Revista Brasileira de Educação Física e Esporte, São Paulo, v.25, p.105-15, 2011. Número especial.

BRASIL. Ministério da Educação. Conselho Nacional de Educação. Diretrizes curriculares nacionais geerais para a educação básica. Brasília: MEC/CNE, 2010.

BRASIL. Ministério da Educação e do Desporto. Secretaria da Educação Fundamental. Referenciais para formação de professores. Brasília: MEC/SEF, 2002.

Parâmetros curriculares nacionais. Brasília: MEC/SEF, 1997.

Referencial curricular nacional para a educação infantil. Brasília: MEC/SEF, 1998a. 
BRASIL. Ministério da Educação e do Desporto. Secretaria de Educação Média e Tecnológica. Parâmetros curriculares nacionais: ensino médio. Brasília: MEC/SEMT, 1998b.

BRASIL. Lei de Diretrizes e Bases da Educação Nacional (Lei n. 9394/96). Brasília: MEC, 1996.

CANEN, A.; MOREIRA, A.F.B. Ênfases e omissóes no currículo. Campinas: Papirus, 2001.

CARDOSO, B. Ensinar a ler e escrever: análise de uma competência pedagógica. 1997. Tese (Doutorado) - Faculdade de Educação, Universidade de São Paulo, São Paulo, 1997.

CARVALHO, J.S.F. De psicologismos, pedagogismos e educação. In: REUNIÃO ANUAL DA ANPED, 21., 1997, Caxambú. Anais.... Caxambú: Associação Nacional dos Profissionais da Educação, 1997. Conferência.

EINSNER, E. Educational objectives: help or hidrance. The School Review, Chicago, n.75, p.250-260, 1967.

IMBERNÓN, F. Formação continuada de professores. Tradução de Juliana dos Santos Padilha. Porto Seguro: Artmed, 2010. LOPES, A.C.; MACEDO, E. Teorias de currículo. São Paulo: Cortez, 2011.

LORO, G.L. O currículo: nos limiares do contemporâneo. Rio de Janeiro: DP\&A, 1999.

PACHECO, J.A. Escritos curriculares. São Paulo: Cortez, 2005.

SACRISTÁN, J.G. O currículo: uma reflexão sobre a prática. Porto Alegre: Artmed, 2000.

SACRISTÁN, J.; PÉREZ GÓMEZ, A.I. Compreender e transformar o ensino. Porto Alegre: Artmed, 2000.

SILVA, T.T. Documentos de identidade: uma introdução às teorias de currículo. 3. ed. Belo Horizonte: Autêntica, 2009. TARDIF, M. Saberes docentes e formação profissional. Rio de janeiro: Vozes, 2000

\begin{tabular}{|c|c|}
\hline $\begin{array}{r}\text { ENDEREÇo } \\
\text { Osvaldo Luiz Ferraz } \\
\text { Escola de Educação Física e Esporte - USP } \\
\text { Av. Prof. Mello Moraes, } 65 \\
\text { 05508-030 - São Paulo - SP - BRASIL } \\
\text { e-mail: olferraz@usp.br }\end{array}$ & $\begin{array}{l}\text { Recebido para publicação: 20/08/2012 } \\
\text { Aceito: 00/08/2012 }\end{array}$ \\
\hline
\end{tabular}

